\title{
Assessment of the effectiveness of non-pharmacological methods in pain relief during labor*
}

\author{
Avaliação da efetividade de métodos não farmacológicos no alívio da dor do parto
}

Evaluación de la efectividad de métodos no farmacológicos en el alivio del dolor del parto

Samara Maria Borges Osório ${ }^{1}$, Lourival Gomes da Silva Júnior ${ }^{1}$, Ana Izabel Oliveira Nicolau²

This is a systematic review that aimed to evaluate the effectiveness of non-pharmacological methods for pain relief during labor. The articles' selection was based on BDENF, PubMed, LILACS and Cochrane Library, published between 2007 and 2012. One analyzed seven studies that assessed the non-pharmacological methods and met the eligibility criteria. It was evident that massage, aromatherapy, immersion bath, acupuncture and acupressure are effective methods to relieve pain during labor, because besides reducing pain perception, they still lower levels of anxiety and stress. Among them, the most efficient one was the massage, mainly when done in the first stage of labor. Furthermore, the interventions don't interfere in the kind and duration of labor, being safe to clinical practice.

Descriptors: Labor Pain; Obstetrical Nursing; Labor, Obstetric.

Revisão Sistemática que objetivou avaliar a efetividade de métodos não farmacológicos no alívio da dor durante o trabalho de parto. A busca de publicações ocorreu na BDENF, Pubmed, LILACS e Cochrane Library, com seleção de 2007 a 2012. Foram analisados sete estudos que avaliaram os métodos não farmacológicos e atenderam aos critérios de elegibilidade. Evidenciou-se que a massagem, a aromaterapia, o banho de imersão, a acupuntura e a acupressão são eficazes métodos para aliviar a dor no trabalho de parto, pois além de diminuírem a percepção dolorosa, ainda reduzem os níveis de ansiedade e de estresse. Dentre eles o que se mostrou mais eficaz foi a massagem, principalmente quando aplicada na primeira fase do trabalho de parto. Além disso, as intervenções não interferem no tipo e na duração do trabalho de parto, mostrando-se seguras à prática clínica.

Descritores: Dor do Parto; Enfermagem Obstétrica; Trabalho de Parto.

Revisión sistemática con objetivo de evaluar la efectividad de métodos no farmacológicos en el alivio del dolor en el trabajo de parto. La búsqueda de las publicaciones ocurrió en BDENF, Pubmed, LILACS e Cochrane Library, con selección de 2007 a 2012. Se analizaron siete estudios que evaluaron los métodos no farmacológicos y que cumplieron los criterios de elegibilidad. El masaje, la aromaterapia, el baño de inmersión, la acupuntura y la acupresión son métodos eficaces para aliviar el dolor en el trabajo de parto, ya que además de reducir la percepción del dolor, aún reducen los niveles de ansiedad y estrés. Entre éstos lo de mayor eficacia fue el masaje, principalmente cuando aplicada en la primera etapa del trabajo de parto. Además, las intervenciones no interfieren en el tipo y en la duración del trabajo de parto, señalándose seguras a la práctica clínica.

Descriptores: Dolor de Parto; Enfermería Obstétrica; Trabajo de Parto. *Extracted from a Nursing monograph entitled “Evaluation of the effectiveness of non-pharmacological methods for pain relief during labor"
Universidade Federal do Piauí, 2012.

${ }^{1}$ Universidade Federal do Piauí. Picos, PI, Brazil.

${ }^{2}$ Universidade Federal do Ceará. Fortaleza, CE, Brazil.

Corresponding author: Ana Izabel Oliveira Nicolau

Av. João Pessoa, 5053. Apto: 604.CEP: 60425813. Fortaleza, CE, Brazil. E-mail: anabelpet@yahoo.com.br 


\section{Introduction}

Labor represents the final stage of conception where the being that was generated will start a life independently of the maternal organism. Promoting comfort and satisfaction to women are among the most important tasks of care providers, who should value the physiological birth and the appropriate use of technology, prioritizing humane care that respects their individuality and autonomy.

In past centuries, mothers were accompanied by experienced women, more commonly called midwives, being their houses the place for attendance. To ease the pain of contractions, the caregivers said prayers, prepared herbal recipes and used charms ${ }^{(1)}$.

With the institutionalization of the birth process and labor, women lost their position as protagonists of birth and started to represent objects during that process, reflecting the power that health professionals have on the transformation of physiological events in technical, interventionist and pathological methods.

The assistance to these women during labor often involves emotional support, physical contact in order to share fear, pain, stress and anxiety, joining forces and stimulating positively the mother in this unique moment as the pain of labor and its duration suffer personal influences. Thus, labor's process of humanization require, besides monitoring by the partner, family or friends, non-pharmacological interventions associated with information received by mothers in their preparation for delivery ${ }^{(2-3)}$.

Moreover, during this natural process, one should offer care focused on the balance of environmental factors in order to allow women to conserve their energy to cope with the pain and its association with pleasant happenings during labor in a less aggressive and painful way. Thus, nonpharmacological interventions are options to replace, as much as possible, anesthetics and analgesics during labor process and delivery ${ }^{(4)}$.

It is essential that non-pharmacological measures of pain relief are exploited because they are safer and tend to cause fewer interventions. Furthermore, pain can be relieved using only these care technologies, resuming the physiological significance that childbirth should pose to both the mother and the newborn.

The implementation of these methods by Nursing is fundamental to its professional autonomy and rescue of its scientific basis. Thus, given the above, one asks: Are non-pharmacological methods effective for pain relief during labor? In order to answer this question this systematic review was conducted.

Starting from this premise, the objective was to evaluate the effectiveness of non-pharmacological methods for pain relief, checking if they interfere with the intensity of the painful sensation during labor.

\section{Method}

This is a Systematic Review (SR) as it gathers in an organized way, lots of results of clinical studies about the effectiveness of non-pharmacological methods of pain relief in childbirth and it helps to explain differences found among primary studies that investigate the same question ${ }^{(5)}$.

The search of studies took place in March 2012, in the Nursing Database (BDENF), in the National Library of Medicine (Pubmed), in the Latin American \& Caribbean Health Sciences Literature (LILACS) and Cochrane Library restricted to publications from 2007 to 2012. In the research were used the controlled descriptors of DECs and Mesh in Portuguese and English: therapeutic bath (banho terapêutico), Massage (massagem), Audio analgesia (Audioanalgesia), Aromatherapy (aromaterapia), Changes of position (mudanças de posição), Breathing techniques (técnicas de respiração), Non-pharmacological methods (métodos não farmacológicos), Pain during labor (dor no parto), Nursing (Enfermagem), Labor (trabalho de parto) and humanized childbirth (parto humanizado).

The articles' selection was based on the following inclusion criteria: being a Controlled Randomized Trial (RCT), or a Systematic Review, 
available electronically in full and written in Portuguese, English or Spanish.

After finding the studies that could possibly be part of this systematic review through the search described previously, each abstract was evaluated as the initial stage of selection. Articles that met the inclusion criteria were obtained and analyzed in full. One emphasizes that two researchers assessed all the abstracts independently so that there was a confirmation of the potential studies to be included. The final version of the studies considered as qualified was shared among the researchers for critical analysis by consensus.

After the choice of studies, data were collected according to the adaptation of a validated instrument, which comprises the following components: identification of the article, host institution of the study, type of journal, methodological characteristics of the study and assessment of methodological rigor $^{(6)}$. In addition, a score was assigned to each study to provide a measure of methodological quality.

The analysis of studies included took place in April and May 2012. Studies were separated according to the following thematic categories: structural aspects of studies, methodological aspects of studies and findings about the use of non-pharmacological techniques for pain relief during labor.

Later tables were compiled in the program Microsoft Office Excel 2007, with absolute data in order to facilitate visualization, interpretation and analysis of data. They were analyzed according to the literature.

\section{Results}

\section{Structural characteristics of the selected studies}

Twenty-two studies that evaluated nonpharmacological methods as therapeutic intervention were analyzed. Out of these, seven met the eligibility criteria.

The profile of the type of production showed that, out of seven, four were scientific articles. Medicine stood out as the area with the biggest number of selected publications, as out of the twentyeight authors, twenty-one were physicians. Nurses were the authors in one of the publications.

Regarding the country of origin of the publications, Brazil (2) is equal to England (2) in the number of studies. This number of countries is small compared to Iran (1), Italy (1) and Austria (1), responsible for three studies. In addition, six studies were in English and one in Portuguese.

Despite being the subject of studies since the $60 \mathrm{~s}$, the effectiveness of non-pharmacological methods continues to be questioned. The years from 2010 through 2012 accounted for four of the productions, being two in 2010 and two after this year.

Out of the seven studies selected, two were RCTs, both with Jadad score equal to 3. It reveals a quality methodological rigor, since this scale has a maximum score of 5 and it considers scores lower than three of poor quality. The remaining studies (five) were systematic reviews. The Jadad scale is a reliable indicator of the quality of studies and it is based on a report about each study in the aspects of randomization, blinding, withdrawals and dropouts from study participants ${ }^{(7)}$. The Systematic Review is recognized as the highest level of evidence among the types of publications.

\section{Methodological characteristics of the selected studies}

The most assessed Non-Pharmacological Methods (NPMs) in the studies were massage and aromatherapy, both studied in four, followed by immersion bath and music therapy, in three. In addition, hypnosis, acupuncture, acupressure and transcutaneous electrical nerve stimulation were explored in two studies. It is worth mentioning that one single study evaluated several non-pharmacological methods.

A description of the characteristics of the study subjects showed that multiparous women were included in four studies, being two with multiparous 
and nulliparous and two with multiparous and primiparous women. Three studies included only primiparous women as research subjects.

Some scholars included all women in labor, including high-risk labors ${ }^{(8)}$. Other researchers included women with single and low-risk pregnancy. In addition, some authors considered women during spontaneous or induced delivery, single or multiple pregnancy, gestational age over 36 completed weeks, fetus in cephalic presentation, births in the first and second stage of labor and preterm births ${ }^{(9)}$.

The most commonly employed method for the measurement of pain was the Visual Analogue Scale (VAS), mentioned in three studies. Two used the McGill pain questionnaire and two used both methods.

Effects of the non-pharmacological methods assessed

The evidence found regarding the use of NPMs for pain relief during labor was expressed according to each method.

\section{Massage}

Four studies evaluated the efficacy of massage, being three SRs and one RCT. The main variables evaluated were pain intensity, kind of labor, admission to the Neonatal Intensive Care Unit (NICU), duration of labor, satisfaction with pain relief, behavioral reaction, stress level, anxiety level, need of analgesia and comparison with music therapy.

Four studies evaluated the pain intensity. During the first stage of labor pain was reduced in the massage group (four studies, 225 women) ${ }^{(8)}$. Findings of another research show that there was a significant reduction in pain perception of women in the massage group compared with the control group (CG) during the three labor phases (first phase: 0.57, CI95\%: 0.840.29; $\mathrm{p}<0.001$; Second Phase: 0.43, CI95\%: 0.71-0.16; $\mathrm{p}<0.01$, Third phase: 0.7, CI95\%: 1.04-0.36; $\mathrm{p}<0.01^{(10)}$.

In fifteen RCTs of one of the studies, the mothers of the experimental group (EG) had reduced pain, and in two studies the reduction was statistically significant in the latent phase of labor. In one of them, the scores of reactions to pain of the EG were significantly lower in the latent, active and transitional phases of labor ( $p=0.000, p=0.002, p=0.000)$. In the other, the EG showed bigger positive facial expressions $(p<0.05)$ and lower body movements $(p<0.001)$ due to pain in the latent phase ${ }^{(9)}$.

A study evaluated the kind of labor and neonatal ICU admission, not showing a significant difference in the number of vaginal deliveries (two studies, 105 women), Cesarean (Two trials, 105 women) and admission to the special unit of baby care (experiment I, 44 women) in trials comparing massage to standard care $^{(8)}$. Did the authors consider these data pertinent to the object of study - the effectiveness of NPMs in pain relief during labor?

In the results found in another study, there was no difference in the duration of labor (WMD 1.35, CI95\%: 0.98-3.68) ${ }^{(10)}$. In the evaluation of three RCTs, two reached the same result and one found a reduction in the duration of labor in the $\mathrm{EG}(\mathrm{p}<0.001)^{(9)}$.

The maternal outcomes related to the management and progress of labor were evaluated in three RCTs, and in two of them there were no differences in any of the evaluated variables (duration of labor, epidural analgesia, cesarean rate, use of forceps, duration of labor and use of drugs).

The variable satisfaction with pain relief was evaluated in two studies. In the first one there was no difference in satisfaction with the childbirth experience in general (ADM-0.47, CI 95\%: 1.07 to $0.13)^{(10)}$. In the second case, the authors examined this variable in two studies. In one of them there was no significant reduction of pain, however, the EG (massage) and placebo (music therapy) had more positive perceptions of labor and bigger sense of control. In the other, the results about satisfaction with the birth were similar among the groups $(\mathrm{p}<0.001)^{(9)}$.

The behavioral reactions resulting from pain, 
stress level and anxiety was assessed in a study ${ }^{(9)}$. Out of the two studies that analyzed the behavioral reactions, in one the pain reactions scores of the EG were significantly lower in the latent, active and transitional phases of labor $(\mathrm{p}=0.000, \mathrm{p}=0.002$ and $\mathrm{p}=0.000$ ). In the other study, the EG showed more positive facial expressions $(\mathrm{p}<0.05)$ and lower body movements $(p<0.001)$ due to pain in the latent phase.

The RCT that assessed the level of stress during labor indicated a lower rate on the EG $(p<0.001)$. The level of anxiety was assessed in two studies: in one, the patients who received the intervention had an anxiety reduction only in the latent phase of labor and on the other, a reduction in all phases.

During the assessment of the need for analgesia and comparison with music therapy, mothers in the massage therapy group had the lowest level of pain compared with the music therapy group $(\mathrm{p}=0.009)$. The most significant difference between the two groups, before and after the interventions was observed in the agonizing phase (most severe pain) with a main difference of 36.3 points (CI95\%: 13.641.4, $\mathrm{p}=0.001$ ). In addition, there was a significant difference between the two groups in terms of pain intensity after the interventions ${ }^{(11)}$.

\section{Aromatherapy}

The effectiveness of aromatherapy was evaluated by four studies distributed as follows: one RCT and three SRs. The variables analyzed were type of delivery, intrapartum events, duration of labor, Apgar score, admission to neonatal ICU, pain perception and analgesic use.

The RCT of one of the studies analyzed, had the participation of 513 eligible mothers (EG: 251 and CG: 262). By employing the intervention, patients could choose one out of five types of essential oils available: Roman chamomile (Chamaemelum nobile), clary sage (Salvia sclarea), frankincense (Boswellia carteri), lavender (Lavandula augustifolium) and mandarin (Citrus reticulata). Each oil used in the study had a certificate of analysis and gas chromatography before its use to ensure that it was free of contaminants. Sweet Almond (Prunus amygdalus) was provided for massage $^{(12) \text {. }}$

According to the kinds of delivery, there was no difference between the aromatherapy group and the control group, and each one of them had the same proportion of vaginal delivery $(89 \%)^{(12)}$. As well as another result in which they did not find benefit of therapeutic intervention concerning the occurrence of spontaneous vaginal delivery (RR 0.93, 95\% CI 0.67 to 1.28 ), instrumental vaginal delivery (RR 0,83 , 95\% CI 0.06-11.70), or a cesarean (RR 2.54, 95\% CI 0.11 to 56.25$)^{(10)}$. Do the authors consider these data pertinent to the object of study - effectiveness of NPMs in the pain relief during labor?

There was no difference in maternal outcomes related to cesarean section (RR 0.99, CI 95\%: 0.701.41); vacuum delivery ( $\mathrm{RR}=1.5,95 \% \mathrm{CI}: 0.31-7.62$ ) and spontaneous vaginal delivery $(\mathrm{RR}=0.99,95 \%$ CI: $0.75-1.3)^{(9)}$. There was not a significant difference between groups (Aromatherapy as standard treatment) in the assisted vaginal deliveries or caesarean sections (RR 1.04, CI 95\%: 0.48-2.28 and RR 0.98, CI 95\%: 0.49-1.94, respectively) ${ }^{(8)}$.

According to the labor duration, it was found that the average length of the first and second stage of labor was the same for each group (217 minutes +217 seconds vs. 216 minutes +130 seconds for aromatherapy and control, respectively, and 35 minutes +26 seconds vs. 33 minutes +23 seconds for aromatherapy and control, respectively ${ }^{(12)}$. No difference was found in the results regarding the duration of the first stage of labor (RR=1.01, 95\% CI: 0.83-1.4 $)^{(9)}$. Only one study evaluated the Apgar score, and the average scores were not different for each group at 1,5 and 10 minutes $^{(12)}$. Do the authors consider these data pertinent to the object of this study - effectiveness of NPMs in pain relief during labor?

There was no significant difference among groups in the admission to the special baby care unit (one study, 513 women) ${ }^{(8)}$. It was also not found a 
reduction in babies' admissions from the EG in the neonatal ICU $(p=0.017)^{(9)}$. However, in another study there was a significant reduction in neonatal ICU admission of children from the aromatherapy group ${ }^{(12)}$.

The data for self-assessment of maternal pain perception using the Likert scale were collected before and 30-40 minutes after receiving aromatherapy. Nulliparous reported a small reduction in pain perception after aromatherapy (75 before versus after 72 after it). Multiparous women reported no significant difference ( 69 before versus 68 after it) ${ }^{(12)}$.

In an investigation there were data about any results of efficacy ${ }^{(8)}$. In another, the pain reduction was more perceived by nulliparous women from the EG before and after the aromatherapy, which did not occur with the multiparous. Pain, anxiety and fear were lower for $86 \%$ of women who received the intervention ${ }^{(9)}$.

One study evaluated the use of analgesics, and there were no differences observed among women who received ginger or lemongrass in the use of analgesics (RR 2.50, CI 95\%: 0.31-20.45)(10).

\section{Immersion bath}

The intervention "immersion bath" was analyzed in three studies, all in SRs. In these were evaluated: the need for analgesics, pain intensity, satisfaction with the method, blood pressure values, duration of labor, type of delivery and Apgar score.

It was evident that water immersion during labor significantly reduces the rate of epidural/spinal analgesia based on data from six studies, and that water immersion during the first stage of labor can be a support for women with low risk of complications. Immersion during the second stage of labor needed to be more investigated, but at the time there was no evidence to support or not to support the decision of a woman to give birth in water ${ }^{(13)}$.

Other researchers analyzed this variable in two studies: in one of them there was a reduction in analgesia in the EG (OR=0.71, CI 95\%: 0.49-1.01). In contrast, the other study found an increase in this rate in the group that started the intervention with dilation less than $5 \mathrm{~cm}(\mathrm{p}=0.0015)^{(9)}$.

With regard to pain intensity, it was found an experience of moderate to severe pain ${ }^{(13)}$. Individual trials comparing water immersion during the firststage of labor without immersion or standard treatment, suggested a reduction in pain (one trial, 120 women). However, in other studies using different measures of pain intensity or measurement in different moments, there was no evidence of difference among groups for pain intensity (trials, 141 women) ${ }^{(8)}$.

Regarding satisfaction with the method, mothers showed a desire to use water for a subsequent labor ${ }^{(13)}$. Another finding suggests an increase in satisfaction with the birth experience for the group where immersion occurred during the second stage of labor (117 women $)^{(12)}$. Do the authors consider these data pertinent to the object of study - the effectiveness of NPMs in pain relief during labor?

The results of an investigation were assessed in three studies. In one of them, the overall experience and maternal satisfaction with childbirth were higher in the CG $(p=0.05)$. In two of them, the EG reported greater satisfaction with the birth experience, and in one such satisfaction was due to greater freedom of movement (RR=1.46, CI95\%: 1.18-1.91) and due to privacy ( $\mathrm{RR}=1.18$; CI95\%: 1.02-1.42) ${ }^{(9)}$. Do the authors consider these data pertinent to the object of study - the effectiveness of NPMs in pain relief during labor?

There was a reduction in blood pressure in one of the SRs, all of which were measured in a trial ${ }^{(13)}$. However, these findings have to be considered in the context of small dimensions, and only two trials had total sample size bigger than 300. In another investigation, the average blood pressure was lower in women from the immersion group (trial with 120 women) during the first stage of labor, but there was no significant evidence among groups of any safety results ${ }^{(8)}$. Do the authors consider these data pertinent to the object of study - the effectiveness of NPMs in 
pain relief during labor?

Only one study evaluated the duration of labor and Apgar score. Regarding the duration of labor, evaluated in almost all RCTs of its study, there was no reduction in any of them, on the contrary, in one case labor was significantly longer in the EG $(p=0.003)^{(9)}$. Do the authors consider these data pertinent to the object of study - the effectiveness of NPMs in pain relief during labor?

Concerning the Apgar score, no significant differences were found regarding the scale among groups. In addition, newborns in the study required more suction ( $57 \%$ vs. $53 \%$ ), oxygen therapy (35\% vs. $27 \%$ ) and mechanical ventilation ( $3 \%$ vs. $1 \%$ ), although without statistical significance. Do the authors consider these data pertinent to the object of study - the effectiveness of NPMs in pain relief during labor?

\section{Music}

Music therapy or audio-analgesia was assessed in three studies: two SRs and one RCT, which included a sample of 50 mothers ( $C G$ and EG). The criteria assessed were pain intensity, satisfaction with pain relief and labor, type of delivery, need for analgesia and comparison with the massage.

There was no evidence of a significant difference in pain reduction (two studies, 74 women, a trial of 66 women) $)^{(8)}$. Two studies analyzed satisfaction with pain relief. For the first, there was no satisfaction (one study, 40 women, one trial of 66 women) and delivery (one study, 66 women). For the second, in a metaanalysis of 25 women, no difference among the groups was found (RR 2.00, CI95\%: 0.82-2.00) ${ }^{(8,10)}$.

As for the type of delivery, fewer assisted vaginal deliveries were observed in two studies comparing music with standard treatment (two trials, 86 women), but no evidence of significant difference was observed in a joint study of the same comparison (one study, 904 women) ${ }^{(8)}$. Do the authors consider these data pertinent to the object of study - the effectiveness of NPMs in pain relief during labor?

In one SR, twelve patients from the music group (24\%) expressed the need for some methods of pain relief after the interventions ${ }^{(10)}$.

Comparing music with massage, it was noticed that mothers in the massage therapy group had the lowest level of pain compared to those in the music therapy group $(p=0.009)$. The most significant difference between the two groups, before and after intervention was observed in the agonizing phase (most severe pain) with a main difference of 36.3 points $(\mathrm{p}=0.001)^{(11)}$.

\section{Acupuncture, acupressure, hypnosis and transcutaneous electrical stimulation}

These methods were analyzed in three SRs. The four interventions were analyzed in a single SR. Acupuncture, acupressure and hypnosis in another SR and TENS in a third SR. The variables were: satisfaction with pain relief, kind of delivery, neonatal ICU admission, Apgar scores, analgesics use and comparison with other methods.

The pain reduction (a study with 120 women) and bigger satisfaction with pain relief (a study with 150 women) were observed in subjects in studies with acupuncture or acupressure compared to no treatment or placebo. There was no evidence of a significant difference of pain and satisfaction with pain relief for other comparisons of acupuncture with placebo or standard care ${ }^{(8)}$.

Comparing TENS in acupuncture points with placebo, fewer women in the TENS group reported severe pain during labor (two studies, 290 women). There was no significant difference observed for pain in two other studies comparing TENS with placebo or usual treatment (two studies, 299 women). In a study comparing TENS in acupuncture points with standard treatment, more women in the TENS group were satisfied with the pain relief (one study, 90 women), but in five trials comparing TENS with placebo or standard treatment, there was no 
difference among the groups concerning satisfaction with pain relief ${ }^{(8)}$.

Women receiving acupressure reported less anxiety compared with women in the control group (75 women) (ADM -1.40 CI 95\%: 2.51-0.29). In a study, there was no difference in maternal satisfaction of pain management between acupuncture and the control groups. In a meta-analysis of 288 women, significant heterogeneity was indicated by statistics and a random effects model was applied. There was no difference in the evaluation of women concerning pain intensity (WMD -0.20, CI 95\%: 0.80-0.40) among groups $^{(10)}$.

One of the SRs analyzed was inconclusive as to the effect of TENS for pain control during labor delivery compared to the placebo group. Moreover, low methodological quality was found in most studies included in this $\mathrm{SR}^{(14)}$.

Fewer assisted vaginal labors (three trials, 704 women) and cesarean sections (one study, 120 women) were observed, comparing acupuncture and acupressure with standard treatment or placebo. There was no evidence of a significant difference between assisted vaginal deliveries (three trials, 414 women) and cesarean sections (three trials, 867 women $)^{(8)}$. Do the authors consider these data pertinent to the object of study - effectiveness of NPMs in pain relief during labor?

There was no difference in the incidence of instrumental delivery between acupuncture and acupressure groups (RR 0.95, CI 95\% 0.45-2.00). A study reported that 90 women found no difference in spontaneous vaginal birth (RR 0.98, CI 95\% 0.89-1.08) or caesarean section (RR 0.96, CI 95\% 0.06-14.83) ${ }^{(10)}$. Do the authors consider these data pertinent to the object of study - effectiveness of NPMs in pain relief during labor?

There was no significant difference in the number of admissions to intensive treatment in the neonatal ICU (two studies, 345 women) for the acupuncture group. Furthermore, no significant difference was found in Apgar score in five and seven minutes (one study, 305 women) ${ }^{(8)}$. Do the authors consider these data pertinent to the object of study - effectiveness of NPMs in pain relief during labor?

In the comparison between acupuncture and injection of sterile water, more women in the sterile water group were satisfied with the pain relief (one study, 128 women). In the other comparisons of acupuncture or acupressure, there was no evidence of significant difference in the number of vaginal or cesarean delivery (MD 18.60, CI 95\%: 11.54-25.66) ${ }^{(8)}$. Do the authors consider these data pertinent to the object of study - effectiveness of NPMs in pain relief during labor?

Women from the acupuncture group (43\%) received no additional analgesics compared with 34 women $(72 \%)$ in the control group (RR 0.56, CI 95\% $0.39-0.81)^{(10)}$.

\section{Discussion}

By the number of scientific articles found it is inferred that the amount of scientific information available is considerable, because besides being gathered, organized, critically evaluated and quantitatively measured, the information is being transformed into knowledge and constantly disclosed. Moreover, the frequency of publishing about this issue demonstrates that this is a matter extensively studied in the health area and it is essential for clinical practice, because it exposes more consistent applicability in the current medical practice ${ }^{(15)}$.

However, Brazil still produces little on this subject, demonstrating the need for the production of more rigorous studies, because only then can they be disseminated nationally and internationally, giving greater credibility to our productions. So it should also be like that with Nursing, profession which is prominent in studies on the theme.

It is understood that the use of complementary therapies is essential for Nursing to establish its professional autonomy. However the knowledge and dissemination of these methods are the basis to boost 
its scientific nature and contribute to the planning of clinical research ${ }^{(5)}$.

The result about the methodological rigor demonstrates that they have a high level of evidence, proving that they may contribute to highlight the predominant findings in the selected scientific production, helping at political, management and health care decisions, in general, and in nursing, more specifically ${ }^{(16)}$.

The measurement of pain is another key point to the veracity of the study. Due to its subjective nature, the accuracy of the pain measurement has been quite questioned. Studies have shown that the VAS is inconsistent to compare individuals but it can be useful with the same patient over time. This is because the magnitude of pain is indicated by marking a line on a scale from 0 to $100 \mathrm{~mm}$, which may lead to underestimation of pain ${ }^{(17)}$.

McGill scale is based on a visual interpretation of pain perception, where patients are asked to choose words from different groups to describe the perceived pain. Thus the level of subjectivity becomes minimal, characterizing the questionnaire as one of the best instruments for the assessment of pain dimensions ${ }^{(18)}$.

Massage: was effective in reducing pain in all phases of labor and women also showed higher satisfaction with pain relief. In addition, massage reduced the level of stress and anxiety in the experimental group $(\mathrm{p}<0.001)$. Do the authors consider these data pertinent to the object of study effectiveness of NPMs in pain relief during labor?

With regard to the type and evolution of labor, this method does not interfere with both. Do the authors consider these data pertinent to the object of study effectiveness of NPMs in pain relief during labor?

Aromatherapy: concerning the kind of delivery there was no difference between the CG and the EG and the proportion of vaginal delivery gets to be equal between them. This method does not interfere in the duration of labor, as well as in the number of admissions of newborns into the neonatal ICU $(\mathrm{p}=0.017)^{(9)}$.

Nulliparous women reported a reduction in pain perception after aromatherapy. This technique also reduced anxiety and fear in women who received the intervention.

Immersion bath: this method significantly reduces the rate of epidural/spinal analgesia, but there is no evidence of reduced pain intensity. There was greater satisfaction with the birth experience for the group where immersion occurred and it seems to reduce blood pressure in pregnant women $(p=0.05)$. Regarding the duration of labor, there was no reduction of it and the study concluded it can be significantly longer in the $\mathrm{EG}(\mathrm{p}=0.003)^{(9)}$.

Music: there was no evidence of significant difference in pain reduction. Fewer vaginal deliveries were observed in the control group, but there was a need to introduce other methods of pain relief after surgery.

Acupuncture, Acupressure, Hypnosis, Transcutaneous Electrical Stimulation: satisfaction with pain relief and less anxiety were observed in the groups that received acupuncture or acupressure. Also in these groups there was no evidence of significant difference between types of delivery (RR 0.95, CI 95\% 0.45-2.00). Women who received TENS complain about severe pain during labor, revealing that this is not a very effective method for pain relief.

\section{Conclusion}

The studies showed that massage, aromatherapy, immersion bath, acupuncture and acupressure are effective methods for pain relief during labor because in addition to reducing pain perception, they lower levels of anxiety and stress.

Among them the most effective one was the massage, especially when applied in the first stage of labor. Besides decreasing the perception of pain and the level of stress and anxiety, mothers who used this intervention did not report the need for pharmacological methods.

Massage, aromatherapy and music therapy 
were the interventions when mothers reported no need for analgesic to relieve pain, unlike the immersion bath and acupuncture. Furthermore, the study concluded that interventions do not interfere in the type and duration of labor, being safe for clinical practice $(\mathrm{p}<0.001)$.

Despite the increasing use of complementary therapies, there is a lack of well-designed RCTs to evaluate the efficacy of many of these therapies for pain management during labor.

It is believed that positive results due to the application of non-pharmacological strategies during labor can be enhanced if they are associated with each other, in a complementary way. Diversity is noticed about when and how to apply interventions among authors. These different approaches may impede a careful analysis of the objective in question. So research with the same methodological rigor is indispensable for future systematic reviews.

Finally the findings of this study point to the need of clinical research, particularly in Nursing, focusing on the use of these and other nonpharmacological strategies for pain relief during labor, aiming to humanize care for women during labor.

\section{Collaborations}

Osorio SMB and Nicolau AIO contributed to the creation, analysis, interpretation of data. Silva Junior LG contributed to the writing of the article and final approval of the version to be published.

\section{References}

1. Vargens OMC, Progianti JM, Silveira ACF. O significado de desmedicalização da assistência ao parto no hospital: análise da concepção de enfermeiras obstétricas. Rev Esc Enferm USP. 2008; 42(2):339-46.

2. Davim RMB, Torres GV. Avaliação do uso de estratégias não farmacológicas no alívio da dor de parturientes. Rev Rene. 2008; 9(2):64-72.
3. Silva LM, Barbieri M, Fustinoni SM. Vivenciando as experiências da parturição em um modelo assistencial humanizado. Rev Bras Enferm. 2011; 64(1):60-5.

4. Moraes MST, Rolim LTA, Enders BC, Farias GM, Davim RMB. Aplicabilidade de estratégias não farmacológicas para alívio da dor em parturientes: revisão integrativa. Rev Enferm UFPE On Line. 2010 [citado 2013 mar 21]; 4(3):131-6. Disponível em: http://repositorio.ufrn.br:8080/jspui/ bitstream/1/3169/1/2010ART_Applicabilityof_ BerthaCruzEnders.pdf

5. Cullum N, Ciliska D, Haynes RB, Marks S. Enfermagem baseada em evidências: uma introdução. Porto Alegre: Artmed; 2010.

6. Ursi ES, Galvão CM. Prevenções de lesões de pele no perioperatório: revisão integrativa da literatura. Rev Latino-Am Enfermagem. 2006; 14(1):124-31.

7. Jadad AR, Moore RA, Carroll D, Jenkinson C, Reynolds DJ, Gavaghan DJ, et al. Assessing the quality of reports of randomized clinical trials: is blinding necessary? Control Clin Trials. 1996; 17(1):1-12.

8. Jones L, Othman M, Dowswell T, Alfirevic Z, Gates $\mathrm{S}$, Newburn $\mathrm{M}$, et al. Pain management for women in labour: an overview of systematic reviews. Cochrane Database Syst Rev. 2012; 3(2):1-40.

9. Gayeski ME, Bruggemann OM. Métodos não farmacológicos para alívio da dor no trabalho de parto: uma revisão sistemática. Texto Contexto Enferm. 2010; 19(4):774-82.

10. Smith CA, Collins CT, Cyna AM, Crowther CA. Complementary and alternative therapies for pain management in labour. Cochrane Database Syst Rev. 2006; (4):CD003521.

11. Taghinejad H, Delpisheh A, Suhrabi Z. Comparison between massage and music therapies to relieve the severity of labor pain. Women's Health. 2010; 6(3):377-81.

12. Burns E, Zobbi V, Panzeri D, Oskrochi R, Regalia A. Aromatherapy in childbirth: a pilot randomized controlled trial. Int J Obstetr Gynacol. 2007; 114(7):838-44.

13. Cluett ER, Burns E. Immersion in water in labor and birth. Cochrane Database Syst Rev. 2009; (2):CD000111. 
14. Mello LFD, Nóbrega LF, Lemos A. Estimulação elétrica transcutânea no alívio da dor do trabalho de parto: revisão sistemática e metanálise. Rev Bras Fisioter. 2011; 15(3):175-84.

15. Porto AMF, Amorim MMR, Souza ASR. Assistência ao primeiro período do trabalho de parto baseada em evidências. Femina. 2010; 38(10):528-37.

16. Lopes ALM, Fracolli LA. Revisão sistemática de literatura e metassíntese qualitativa: considerações sobre sua aplicação na pesquisa em enfermagem. Texto Contexto Enferm. 2008; 17(4):771-8.

17. Bottega FH, Fontana RT. A dor como quinto sinal vital: utilização da escala de avaliação por enfermeiros de um hospital geral. Texto Contexto Enferm. 2010; 19(2):283-90.

18. Araújo LG, Lima DM, Sampaio RF, Pereira LS. Pain locus of control scale: adaptation and reliability for elderly. Rev Bras Fisioter. 2010; 14(5):438-45. 